\title{
Development of Low Calcium Flyash Based Geopolymer Concrete
}

\author{
Kolli Ramujee, Member, IACSIT and M. Potharaju
}

\begin{abstract}
Geopolymer concrete is a cement less concrete gaining popularity globally towards the sustainable development .It is a type of amorphous alumino-silicate cementitious material which can be synthesized by polycondensation reaction of geopolymeric precursor and alkali polysilicates. Beside fly ash, alkaline solution is utilized to make geopolymer paste which binds the aggregates to form geopolymer concrete. Even though some studies could be seen in literature on geopolymer concrete, not much work has been reported in the area of development of mix design procedure.In addition, some of the conclusions are contradictory. In this paper an attempt is made to develop the mix design for Geopolymer concrete in medium grade and relative comparison has been made with equivalent mix proportions of grade of OPC Concrete in both heat cured and ambient cured conditions. About 7 different mixes for each grade is casted, tested and optimized .The design parameters like alkaline liquid to flyash ratio and water to Geopolymer solids ratio were proposed to develop the Geopolymer concrete of standard grade.
\end{abstract}

Index Terms - Compressive strength, flyash, geopolymer, molarity.

\section{INTRODUCTION}

The production of Portland cement, a main component of making concrete, contributes significant amount of greenhouse gas, because the production of one ton of Portland cement also releases about one ton of carbon dioxide gas into the atmosphere [1].Therefore, the introduction of a novel binder called 'geopolymer' by Davidovits [2], [3] promises a good prospect for application in the concrete industry as an alternative binder to Portland cement. In terms of reducing global warming, the geopolymer technology could reduce the $\mathrm{CO}_{2}$ emission to the atmosphere caused by cement and aggregates industries by $80 \%$ [4]. Inspired by this novel technology and the fact that fly ash is a waste material abundantly available, an attempt has been made to develop an alternative concrete binder by applying the geopolymer technology and utilizing fly ash as the source material to produce the Fly Ash-Based Geopolymer Concrete.Hardjito, et al. [5] introduced the early work on fly ash-based geopolymer concrete dealing with the manufacturing process and the effect of curing period, curing temperature and the age of concrete on the compressive strength of fly ash-based geopolymer concrete. Moreover, the effect of alkaline ratio and the ratio of alkaline to water was also studied. More research results on the factors

Manuscript received February 10, 2013; revised July 17, 2013.

K. Ramujee is with the V.N.R.V.J. Institute of Engineering \& Technology, Hyderabad, India (e-mail: ramujee_k@vnrvjiet.in)

M. Potharaju is with GITAM University, Visakhapatnam, India. affecting the compressive strength and other properties of fresh and hardened fly ash-based geopolymer concrete were also reported [6]-[8]. Attempts to apply this material as a structural material have geopolymer concrete beams and columns [9] been carried out by studying the behavior and strength of reinforced fly ash-based geopolymer concrete beams and columns [9]. This paper presents the study on fly ash-based geopolymer concrete, focused on mix design for three grades i.e. low, medium and higher grades have been arrived and tested for compressive strength.

\section{GEOPOLYMER CONCRETE}

Davidovits $(1988 ; 1994)$ proposed that an alkaline liquid could be used to react with the silicon ( $\mathrm{Si}$ ) and the aluminum (Al) in a source material of geological origin or in by-product materials such as fly ash and rice husk ash to produce binders. Because the chemical reaction that takes place in this case is a polymerization process, he coined the term 'Geopolymer' to represent these binders.

Geopolymers are members of the family of inorganic polymers. The chemical composition of the geopolymer material is similar to natural zeolitic materials, but the microstructure is amorphous. The polymerization process involves a substantially fast chemical reaction under alkaline condition on Si-Al minerals, those results in a three-dimensional polymeric chain and ring structure consisting of Si-O-Al-O bonds. The Lierature (2-4), reveals that water is released during the chemical reaction that occurs in the formation of geopolymers. This water, expelled from the geopolymer matrix during the curing and further drying periods, leaves behind discontinuous nano-pores in the matrix, which provide benefits to the performance of geopolymers. The water in a geopolymer mixture, therefore, plays no role in the chemical reaction that takes place; it merely provides the workability to the mixture during handling. This is in contrast to the chemical reaction of water in a Portland cement concrete mixture during the hydration process.

\section{Fly ASh-BASEd GeOPOLYMER CONCRETE}

Geopolymer concrete is manufactured using source materials that are rich in silica and alumina. While the cement-based concrete utilizes the formation of calcium-silica hydrates (CSHs) for matrix formation and strength, geopolymers involve the chemical reaction of alumino-silicate oxides with alkali polysilicates yielding polymeric $\mathrm{Si}-\mathrm{O}-\mathrm{Al}$ bonds [4], [5].

In this experimental work, fly ash is used as the source 
concrete. The manufacture of geopolymer concrete is carried out using the usual concrete technology methods. As in the Portland cement concrete, in fly ash-based geopolymer concrete, the aggregates occupy the largest volume, i.e. about $75-80 \%$ by mass.

Sodium-based activators were chosen because they were cheaper than Potassium-based activators. The sodium hydroxide was used, in flake or pellet form. It is recommended that the alkaline liquid is prepared by mixing both the solutions together at least 24 hours prior to use. The mass of $\mathrm{NaOH}$ solids in a solution varied depending on the concentration of the solution expressed in terms of molar, $\mathrm{M}$. The concentration of sodium hydroxide solution can vary in the range between 8 Molar and 16 Molar. The mass of water is the major component in both the alkaline solutions. In order to improve the workability, a melamine based super plasticizer has been added to the mixture.

\section{Mixture Proportions of GeOPOlyMER CONCRETE}

The primary difference between Geopolymer concrete and Portland cement concrete is the binder. The silicon and aluminium oxides in the low -calcium flyash reacts with the alkaline liquid to from the geopolymer paste that binds the loose coarse and fine aggregates and other unreacted materials to form the geopolymer concrete. As in the case of Portland cement concrete the coarse and fine aggregates occupy about $75 \%$ to $80 \%$ of the mass of Geopolymer concrete [10]. This component of Geopolymer concrete mixtures can be designed using the tools currently available for Portland cement concrete. The compressive strength and workability of geopolymer concrete are influenced by the proportions and properties of the constituent materials that make the geopolymer paste.

Experimental results have shown the following (4-6)

- As the $\mathrm{H}_{2} \mathrm{O}-\mathrm{Na}_{2} \mathrm{O}$ molar ratio increases , the compressive strength of Geopolymer concrete decreases

- Higher the concentration of Sodium hydroxide solution results in higher compressive strength of geopolymer concrete.

- Higher the ratio of Sodium silicate to Sodium hydroxide by mass higher the compressive strength.Based on the above guide lines the trial mixture is designed as follows. The preliminary investigation comprises of determining the chemical composition of flyash, properties of aggregates, properties of cement, properties of alkaline solutions have been shown in Table I, II, III, IV\&V respectively.

\section{Example DESIGN MIX OF G 40. \\ Design stipulations}

Assume density of aggregate as unit weight of concrete = $2400 \mathrm{~kg} / \mathrm{m}^{3}$.

Mass of Combined aggregate $=75-80 \%$ (consider $0.77 \%$ )

$$
=2400 \times 0.77 \%=1848 \mathrm{~kg} / \mathrm{m}^{3}
$$

now, mass of combined aggregate $=1848 \mathrm{~kg} / \mathrm{m}^{3}$

Mass of Fly ash and alkaline Liquid $=2400-1848=552 \mathrm{~kg} / \mathrm{m}^{3}$

let us take alkaline liquid to fly ash ratio as 0.4 .

Now the mass of fly ash $=(552) /(1+0.4)=394.28 \mathrm{~kg} / \mathrm{m}^{3}$

Mass of alkaline liquid $=552-394.28=157.21 \mathrm{~kg} / \mathrm{m}^{3}$

Let us consider the ratio of $\mathrm{NaOH}$ to $\mathrm{Na}_{2} \mathrm{SiO}_{3}$ as 2.5 .
Now mass of NaoH solution $=(157.21) /(1+2.5)=45.06 \mathrm{~kg} / \mathrm{m}^{3}$ Mass of $\mathrm{Na}_{2} \mathrm{SiO}_{3}$ solution $=157.21-45.06=112.64 \mathrm{~kg} / \mathrm{m}^{3}$

Now calculating the total amount of mass of water and mass of solids in the sodium hydroxide and sodium silicate solution,

\section{Sodium Hydroxide solution $(\mathrm{NaOH})$ :}

Considering $16 \mathrm{M}$ concentration, where in the solution consists of $44.4 \%$ of solids (pallets) and $63.5 \%$ of water.

Mass of solids $=(44.4 / 100) \times(45.06)=20.00 \mathrm{Kg}$

Mass of water $=45.06-20.00=25.06 \mathrm{Kg}$

Sodium Silicate Solution $\left(\mathrm{Na}_{2} \mathrm{SiO}_{3}\right)$ :

The water content in the silicate solution in observed as $63.5 \%$.So, the Mass of Water $=(63.5 / 100) \times(112.64)=$ $71.52 \mathrm{Kg}$ Mass of solids $=112.64-71.52=41.11 \mathrm{Kg}$

\section{Total mass of water:}

mass of water in $\mathrm{NaOH}$ solution + mass of water in $\mathrm{Na}_{2} \mathrm{SiO} 3$. solution $=25.60+71.52=96.58 \mathrm{Kg}$.

\section{Total mass of solids:}

mass of solids in $\mathrm{NaOH}$ solution + mass of solids in $\mathrm{Na}_{2} \mathrm{SiO}_{3}$ solution + mass of Fly ash $=20.00+41.11+394.28=455.39$

$\mathrm{Kg}$. Ratio of water to Geopolymer Solids :

Ratio $=(96.58) /(455.39)=0.21$.

Mixture proportion are shown in Table II

TABLE I: CHEMICAL COMPOSITION FLYASH

\begin{tabular}{|l|l|}
\hline Oxides & Percentage \\
\hline $\mathrm{SiO}_{2}$ & 60.54 \\
\hline $\mathrm{Al}_{2} \mathrm{O}_{3}$ & 26.20 \\
\hline $\mathrm{Fe}_{2} \mathrm{O}_{3}$ & 5.87 \\
\hline $\mathrm{CaO}$ & 1.91 \\
\hline $\mathrm{MgO}$ & 0.38 \\
\hline $\mathrm{K}_{2} \mathrm{O}+\mathrm{Na}_{2} \mathrm{O}$ & 1.02 \\
\hline $\mathrm{SO}_{3}$ & 0.23 \\
\hline Loss on ignition & 2.0 \\
\hline
\end{tabular}

TABLE II: PROPERTIES OF AGGREGATES [11], [12]

\begin{tabular}{|l|c|c|}
\hline Property & Coarse Aggregate & $\begin{array}{c}\text { Fine } \\
\text { Aggregate }\end{array}$ \\
\hline Specific gravity & 2.78 & 2.63 \\
\hline Water absorption & $0.50 \%$ & $1 \%$ \\
\hline Fineness modulus & 7.21 & 2.40 \\
\hline Bulk density $(\mathrm{Kg} / \mathrm{m} 3)$ & 1675 & 1570 \\
\hline source & Crushed granite stone & River sand \\
\hline
\end{tabular}

TABLE III: PROPERTIES OF CEMENT [13]

\begin{tabular}{|l|l|}
\hline Standard consistency & $32 \%$ \\
\hline Intial setting time & $115 \mathrm{~min}$ \\
\hline Final setting time & $240 \mathrm{~min}$ \\
\hline Specific gravity & 3.10 \\
\hline Soundness & $1 \mathrm{~mm}$ \\
\hline Compressive strength $(\mathrm{MPa})$ & 40.1 \\
7 days & 56.0 \\
\hline
\end{tabular}

TABLE IV: PROPERTIES OF SODIUM SILICATE SOLUTION

\begin{tabular}{|l|l|}
\hline Specific gravity & $1.56-1.66$ \\
\hline $\mathrm{Na}_{2} \mathrm{O}$ & $15.5-16.5$ \\
\hline $\mathrm{SiO}_{2}$ & $31-33$ \\
\hline Weight ratio & 2 \\
\hline Molar ratio & 2 \\
\hline
\end{tabular}


TABLE V: PROPERTIES OF SODIUM HYDROXIDE NAOH

\begin{tabular}{|l|l|}
\hline Molar mass & $40 \mathrm{~g} / \mathrm{mol}$ \\
\hline Appearance & White solid \\
\hline Density & $2.1 \mathrm{gr} / \mathrm{cc}$ \\
\hline Melting point & $318^{0} \mathrm{C}$ \\
\hline
\end{tabular}

\section{EXPERIMENTAL PROGRAM}

The sodium hydroxide flakes were dissolved in distilled water to make a solution with a desired concentration at least one day prior to use. The fly ash and the aggregates were first mixed together in a pan mixer for about three minutes.

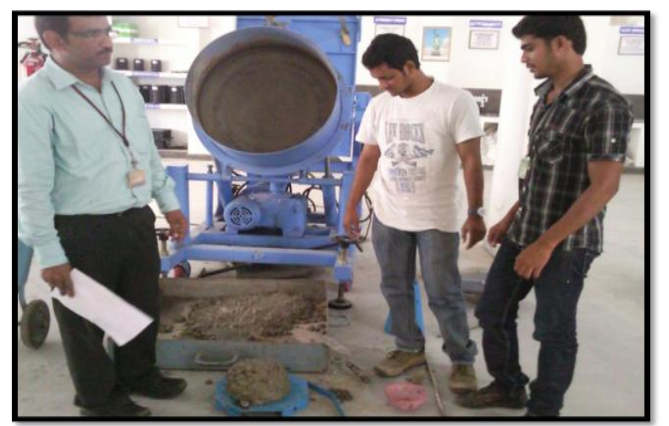

Fig. 1. Pan Mixture used for mixing the proportions of geopolymer concrete.

The sodium hydroxide and the sodium silicate solutions were mixed together with superplasticizer then added to the dry materials and mixed for about four minutes. The fresh concrete was cast into the molds immediately after mixing, in three layers and compacted with manual strokes and vibrating table. After casting, the specimens were cured at $60^{\circ} \mathrm{C}$ for 24 hours. Two types of curing were applied, Heat curing and Ambient curing. For heat curing, the specimens were cured in an oven as shown in Fig. 2 and for Ambient curing the specimens were left to air for desires period.

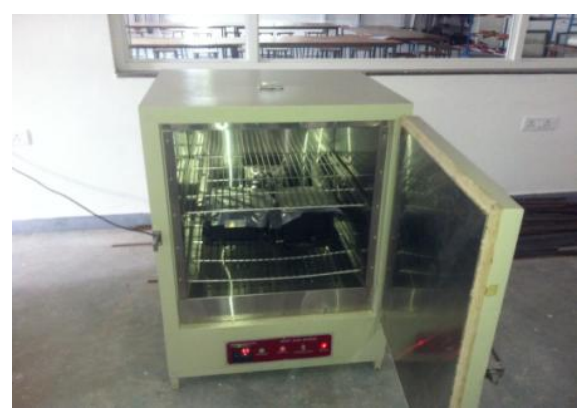

Fig. 2. Specimens wrapped with polythene cover in oven curing

The heat cured specimens were left to air-dry in the laboratory for the next six days until testing on the 7 th day and $28^{\text {th }}$ day.

For the designated grade of Geopolymer concrete mix about 7 mixture proportions were tested and optimized by taking the mix which is giving maximum compressive strength at 28 days under Heat curing (Oven curing) and Ambient cured conditions.

Based on earlier research conducted in Materials testing lab by the author, the following parameters were maintained constant throughout the Experimental work. The parameters are

- The ratio of sodium silicate to sodium hydroxide $=2.5$

- The curing Temperature $=60^{\circ} \mathrm{C}$

- The curing duration $=24 \mathrm{Hrs}$
- Ratio of Fine aggregate to total Aggregate $=0.35$

The other parameters vary between different grades of concrete.

The Concentration of $\mathrm{NaOH}$ is kept constant i.e. $16 \mathrm{M}$ for G40 grade concretes mix the alkaline solution to flyash ratio was 0.40 .

The Final Mixture proportions after optimization are shown below. Table VI displays the mixture proportions of the geopolymer concrete in this research. The equivalent mix proportions of control mix i.e. M40 is shown in Table VII.

TABLE VI: OPTIMIZED MIX PROPORTIONS FOR VARIOUS GRADES OF GEOPOLYMER CONCRETE $\left(\mathrm{KG} / \mathrm{M}^{3}\right)$

\begin{tabular}{|c|c|}
\hline Grade of GPC & G40 \\
\hline Fly ash & 394.3 \\
\hline Fine Aggregate & 646.8 \\
\hline Coarse Aggregate & 1201.2 \\
\hline $\mathrm{NaOH}$ concentration & $45.06(16 \mathrm{M})$ \\
\hline $\mathrm{Na}_{2} \mathrm{SiO}_{3}$ & 112.64 \\
\hline Extra water & ------ \\
\hline Super plasticizer (GLENIUM) & $4 \%$ \\
\hline Ratio of Mixture proportions & $1: 1.64: 3.04$ \\
\hline Liquid/binder ratio & 0.40 \\
\hline \multirow[t]{2}{*}{ Water/geopolymer Solids ratio } & 0.21 \\
\hline & $\begin{array}{l}\text { Heat cured specimens } \\
60^{\circ} \mathrm{C} \text {,for } 24 \mathrm{hrs}\end{array}$ \\
\hline \multirow{4}{*}{$\begin{array}{l}\text { Compressive } 3 \\
\text { strength@ } 7 \\
\text { days } 28\end{array}$} & 43.20 \\
\hline & 45.00 \\
\hline & 50.00 \\
\hline & Ambient cured specimens \\
\hline \multirow{3}{*}{$\begin{array}{l}\text { Compressive } 3 \\
\text { strength@ } 7 \\
\text { days } 28\end{array}$} & 7.92 \\
\hline & 21.40 \\
\hline & 46.8 \\
\hline
\end{tabular}

The control mix of M40 of OPC concrete made by varying water cement ratio to achieve the same level of strength with Geopolymer concrete.

TABLE VII: MIX PROPORTIONS OF COUNTERPARTS (MIX PROPORTIONS OF OPC CONVENTIONAL CONCRETE EXPRESSED AS EQUIVALENT PROPORTIONS OF GPC)

\begin{tabular}{|l|c|}
\hline Grade of concrete & M40 \\
\hline Cement & 394.3 \\
\hline Fine Aggregate & 646.8 \\
\hline Coarse Aggregate & 1201.2 \\
\hline Water & 157.7 \\
\hline Super plasticizer & 4 \\
\hline Mix Proportion & $1: 1.64: 3.04$ \\
\hline W/C ratio & 0.40 \\
\hline \multicolumn{2}{|c|}{ Compressive strength Mpa. Water cured } \\
\hline \multirow{2}{*}{37 days } & 23.3 \\
\cline { 2 - 2 } 28 & 31.6 \\
\cline { 2 - 2 } & 48.8 \\
\hline
\end{tabular}

\section{RESULTS AND DISCUSSIONS}

Based the Experimental investigations carried out on low, medium \& high strength geopolymer concrete, the concluded data can be presented in the following form.

Compressive strength tests were performed at the age of, 7 and 28 days in accordance with IS:516-1959 [14] under 2000KN Compression testing machine with uniform rate of load application for Geopolymer concrete mixes and control 
mixes. It can be seen from the results that the compressive strength increases with increase in the flyash content and decrease of water to geopolymer solids ratio for all ages. It is also observed that $90 \%$ of strength is achieved within 7 days and there is not much variation in strength after 7 days under heat cured conditions. It is observed that the strength development of Geopolymer concrete is slow under ambient conditions and $100 \%$ strength achieved at 28 days only.

The behavior of Geopolymer concrete is similar to their counterpart mix (Conventional mix). The Influence of alkaline liquid to flyash ratios and molar concentrations of $\mathrm{NaOH}$ on the compressive strengths geopolymer concretes for G40 grade is shown in Fig. 3.

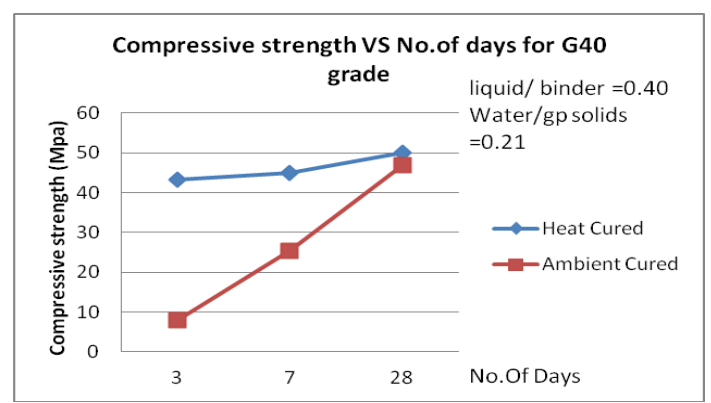

Fig. 3. Variation of compressive strength with no.of days

Compressive strengths are found to decrease with increase in alkaline liquid to flyash ratios even though higher activator (Alkaline liquid) to binder (flyash) ratio effectively contains a higher amount of activating alkali. It shows that higher porosity is created because of increased amount of the activating solution and the substantial increase in number of pores as a result of increase in pores due to heat curing.

\section{CONCLUSION}

1) From the investigation it is clear that for Water/binder ratio \& alkaline liquid/Flyash ratio are the governing factors in designing the Geopolymer mix design for various grades. The Water/binder ratio 0.21 and Alkaline liquid to flyash ratio of 0.40 are suggested for $\mathrm{G} 40$ which indicates improvement in compressive strength of geopolymer concrete can be achieved by decreasing water binder ratio.

2) The compressive strength attained at 28 days for Geopolymer concrete under ambient curing is almost equal to compressive strength achieved by Geopolymer concrete at 7 days. Because of the slow reactivity of flyash at ambient temperature, considerable heat must be applied to increase the geopolymerization process.

3) The decrease in water content favors the formation of geopolymerization process, which demands for increase of concentration of Sodium hydroxide and sodium silicate silicates.Hence increase in concentration of $\mathrm{NaOH}$ results in increase of compressive strength .Hence it is recommended $16 \mathrm{M}$ concentrations for medium grade.

4) It is recommended to add Superplasticizers for high strength Geopolymer concretes, which is analogous to Conventional concrete of higher grades to secure required workability.

5) It also reported that unlike in the past literature, inclusion of high alkaline solution content to the mix need not increases the strength which can be seen from reported Geopolymer mixes in the present work.

\section{REFERENCES}

[1] J. Davidovits, "Geopolymer chemistry and properties," in Proc. Geopolymer '88, First European Conference on Soft Mineralogy, The Geopolymer Institute, Compiegne, France, 1988, pp. 25-48.

[2] J. Davidovits, "Soft mineralogy and geopolymers," in Proc. Geopolymer '88, First European conference on Soft Mineralogy, The Geopolymer Institute, Compiegne, France, 1988, pp. 19-24.

[3] J. Davidovits, "Global warming impact on the cement and aggregates industries," World Resource Review, vol. 6, no. 2, pp. 263-278, 1994.

[4] D. Hardjito, S. E. Wallah, and B. V. Rangan, "Study on engineering properties of fly ash-based geopolymer concrete," Journal of the Australasian Ceramic Society, vol. 38, no. 1, pp. 44-47, 2002.

[5] D. Hardjito, S. E. Wallah, D. M. J. Sumajouw, and B. V. Rangan, "Factors influencing the compressive strength of fly ash-based geopolymer concrete," Civil Engineering, High Performance Concretes and Smart Materials Dimension (Dimensi Teknik Sipil), vol. 6, no. 2, pp. 88-93, 2004.

[6] D. Hardjito, S. E. Wallah, D. M. J. Sumajouw, and B. V. Rangan, "On the development of flyash-based geopolymer concrete," ACI Materials Journal, vol. 101, no. 6, pp. 467-472, 2004.

[7] E. I. D. Lota, E. N. allouche, and S. Vaidya "Mechanical properties of Flyash based Geopolymer concrete, " ACI Materials Journal, vol. 108, no. 3, pp. 300-306, May-June 2011.

[8] D. Hardjito, S. E. Wallah, D. M. J. Sumajouw, and B. V. Rangan, "Fly ash-based geopolymer concrete," Australian Journal of Structural Engineering, vol. 6, no. 1, pp. 77-86, 2005.

[9] D. M. J. Sumajouw, D. Hardjito, S. E. Wallah, and B. V. Rangan, "Behaviour and strength of geopolymer concrete columns," in Proc. 18th Australasian Conference on the Mechanics of Structures and Materials, Perth, Australia, Ed. A.A. Balkema, vol. 1, 2004, pp. 175-180.

[10] A. M. Neville, Properties of Concrete, Fourth and Final ed., Pearson Education, Longman Group Essex, England, 2000.

[11] Method of Test for Aggregate Concrete, Bureau of Indian Standards, IS-2386-1963.

[12] Specification for Coarse and Fine Aggregates from the Natural Sources for Concrete, Bureau of Indian Standards, IS: 383-1970.

[13] Method for Physical Tests for Hydrated Cement, Bureau of Indian Standards, IS: $4031-1988$.

[14] Method of Test for Strength of Concrete, Bureau of Indian Standards, IS: 516-1959.

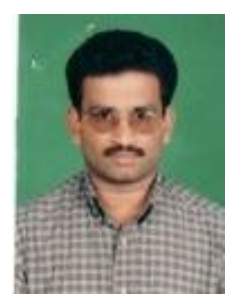

K. Ramujee received his M. Tech in Structural Engineering from the JNT University, Hyderabad in 1997. He is a life member of Indian society for Technical Education (ISTE), India and International society for computer science and Information Technology (IACSIT).

He is currently pursuing Ph.D. and working as an associate professor in Post graduation department of Structural Engineering, VNRVignana Jyothi Institute of Engineering \& Technology, Hyderabad, India. He is having overall teaching \& Industrial experience of 15 years. His major research interests are materials for sustainable development, Behavior of concrete composites due to fire and Finite element analysis of structures. He has published more than 14 papers in the International, National conferences and Journals.

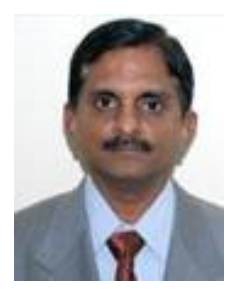

M. Potha Raju received his Ph.D. degree from Andhra University, Visakhapatnam, India in 1998. He is a fellow of Institution of Engineers, Indian association for Structural Engineers. He is currently working as a professor of civil Engineering, GITAM University, Visakhapatnam. He is having a Teaching experience of 20 years and 10 years in research. His major research interests are Behavior of concrete composites subjected to fire, Recycled aggregate concrete etc. He has completed various research projects funded by AICTE and DST etc. He has published more than 50 papers in International and National Journals and Conferences. He has conducted various International and National conferences and workshops .He has guided the PhD Scholars and has been supervising the $\mathrm{PhD}$ and $\mathrm{M}$. Tech projects. 